\title{
Improve Power Stability \& Damping Oscillation in Multi Machine System Using (SSSC) with POD Controller
}

\author{
Rizan A. Ali, Ergun Ercelebi
}

\begin{abstract}
In current days the Power system is heavily loaded, due to the continuous demand in electric this causes to instability there may be insufficient active and reactive power. This paper explains a proper approach to compensate the active and reactive power and also damping oscillations in a Multi-machine system consisting of four machines six bus, using Static Synchronous Series Compensator (SSSC) that can be considered one of the most significant series compensation FACTS family uses in power transmission systems. Both single phase and three phase faults have been considered in the study. Simulations have been done in MATLAB/SIMULINK software in three cases; Without SSSC, With SSSC without controller, SSSC with Power System Controller (POD). Simulation result demonstrates that Without SSSC, the system becomes unstable during faults. When SSSC is forced in the network, then system becomes stable. In the case when SSSC with POD, then system parameters become stable in faster way than without controller. So with PSC the system performance is greatly improved and power system oscillations are damped out very quickly.
\end{abstract}

Keywords-Facts Controllers Static Synchronous Series Compensator (SSSC); Power Oscillation Damper (POD);MATLAB Simulink.

\section{INTRODUCTION}

A FTER widespread research and development, the flexible AC transmission system devices are considered now to be a mature and proven technology. The controllability and the flexibility that the devices are observed to provide the most efficient and reliable solutions when it comes to power systems. The flexible AC transmission systems (FACTS) can then be defined as the transmission systems of alternating current that incorporate in them electronics based on power and other controllers that are static to improve the capability of power transfer and controllability. Tentatively, their main aim is to supply reactive power that is either capacitive or inductive, while improving the quality of transmission and power system stability both dynamic \& transient stability, voltage stability, less active and reactive power loss, voltage regulation [1].

One member of the flexible AC transmission systems (FACTS) device is Static Synchronous Series Compensator (SSSC) that consists of a voltage-sourced converter and a transformer connected in series with a transmission line [2]. The Static

Rizan A. Ali, Ergun Ercelebi are with the Department of Electrical and Electronic Engineering University of Gaziantep, Gaziantep, Turkey
Synchronous Series Compensator (SSSC) device injects a voltage that is both sinusoidal and controllable that remains in series with the network transmission. The voltage source that has been injected imposes reactance that is virtual in the power line, which then regulates the flow of power in the transmission lines. Additionally, this controlling the flow of power line remains to be independent of the line's current magnitude [3].

A SSSC can be externally controlled through the use of designed power system controller that significantly improves the dynamic and steady state performance in large scale power system. It is the dynamic nature of the SSSC that is associated with the use of thyristor devices, such as IGCT and GTO. The ability of the static synchronous series compensator(SSSC) device to function both in the modes that are capacitive and inductive makes it efficient in regulating the flow of power in the system. In either inductive or capacitive modes, the voltage that is injected remains to be in a state of quadrature with the current in the line and therefore acts as inductive or capacitive reactance that is in series with the lines of transmission. The quadrature component of the injected voltage can be leading or lagging the line current by $90^{\circ}$ such that the reactive power is absorbed or generated [4], [5].

Power system oscillations are a greater problem and they are offering a challenge to electric and control engineers for many years. In a difficult state, these oscillations are very insufficiently damped in some cases, and its effect causes a mechanical exhausting of the generation units and unwanted power differences through the transmission lines and increasing the load over the transmission lines. This case will allow the supplementary control laws to supply a best damp for these bother oscillations by using PODs applications.

\section{CONTROL CONCEPT OF SSSC}

The SSSC does not utilize any active source of power, and thus the injected voltage is forced to stay in quadrature with the line current. By varying the magnitude $\mathrm{Vq}$ of the voltage that is injected in the quadrature with current, then the SSSC performs variable reactance compensator functions, which are either inductive or capacitive. The variations in the injective voltage are thus performed through VSC (Voltage-Sourced Converter) that is connected on the secondary section of the coupling transformer [13]. . Also, the VSC utilizes forced commutates power electronic devices to synthesize a voltage from a source of DC voltage. The following diagram demonstrates the process 
of synthesizing voltage from a source of DC voltage. Fig (1) shows the connection of SSSC with transmission line [6].

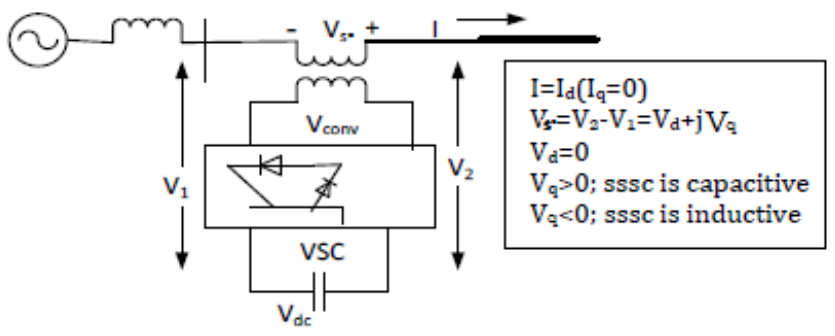

Fig.1 Connection diagram of SSSC with transmission Line

The diagram illustrates how a capacitor that is connected on the side of the DC acts as the source of DC voltage. Also, a small active power should be drawn from the transmission line to ensure that capacitor is kept charged, as well as to provide VSC and transformer losses such that the injected voltage $\mathrm{Vs}^{\mathrm{e}}$ remains 90 degrees out of phase with current I. also, the block diagram presented in the figure designate the converter voltage components, which, are in quadrature and in phase [6]. To represent the power flow through the transmission line basic equations are given by:

$$
\begin{aligned}
\mathrm{P}= & \frac{\mathrm{VsVr}}{\mathrm{XL}} \sin (\delta \mathrm{s}-\delta \mathrm{r})=\frac{\mathrm{V} 2}{\mathrm{XL}} \sin \delta \\
\mathrm{Q}= & \frac{\mathrm{VsVr}}{\mathrm{XL}}(1-\cos (\delta \mathrm{s}-\delta \mathrm{r})) \\
= & \frac{\mathrm{V} 2}{\mathrm{XL}} *(1-\cos \delta)
\end{aligned}
$$

Where: Vs, Vr are sending and receiving end voltages.

$\delta s, \delta r$ are the phase angles of the voltage sources $\mathrm{Vs}$ and $\mathrm{Vr}$ respectively. For simplicity, the voltage magnitudes are chosen such those $\mathrm{Vs}=\mathrm{Vr}=\mathrm{V}$ and the difference between the phase angles is:

$$
\delta=\delta \mathrm{s}-\delta \mathrm{r}
$$

SSSC is capable of emulating a compensating reactance Xq (both inductive and capacitive) in series with the transmission line inductive reactance XL, Therefore, the expressions for power flow given in equation $(1 \& 2)$ becomes:

$$
\begin{aligned}
& P_{q}=\frac{V^{2}}{X_{\text {eff }}} \sin \delta=\frac{V^{2}}{X L\left(1-\frac{X_{q}}{X_{L}}\right)} \sin \delta \\
& Q_{q}=\frac{V^{2}}{X_{\text {eff }}}(1-\cos \delta)=\frac{V^{2}}{X L\left(1-\frac{X_{q}}{X_{L}}\right)}(1-\cos \delta)
\end{aligned}
$$

Where: Xeff is the effective reactance of the transmission line between its two ends, including the emulated variable reactance inserted by the injected voltage source of the Static Synchronous Series Compensator (SSSC). when the SSSC is operated in an inductive mode compensating reactance $\mathrm{Xq}$ is defined to be negative and positive when the SSSC is operated in a capacitive mode.

\section{SSSC-BASED DAMPING CONTROLLER}

To modulate the SSSC injected voltage the structure used in this paper is the lead-lag structure as shown in Fig.2.

This structure consists of a gain block, washout block and two stage lead-lag blocks. The gain block is used to dampen the oscillations. The two stage lead-lag blocks (time constants T1S, T2S, T3S and T4S) provide suitable phase-lead characteristics to compensate for the phase lag between input and the output signals. The washout block acts as a high pass filter with the time constant $\mathrm{Tw}$ to allow signals related with oscillations to pass as it is. The inputs to the POD controller are the voltage at Bus no.4 and the current flowing in Line 2.The Power Oscillation Damping Controller takes input as Vabc , Iabc \& it convert it as power. If no faults has happen then switch will remains open. But the switch is closed when fault happen. After filtering or damp out oscillation, it also gives an error signal and finally two error signal has been added, this is Vqref [4], [7].

$$
\mathrm{Vq}=\mathrm{Vqref}+\Delta \mathrm{Vq}
$$

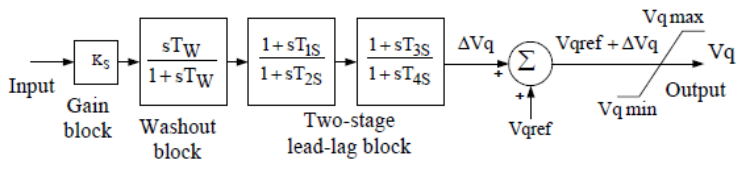

Fig. 2 POD controller design structure

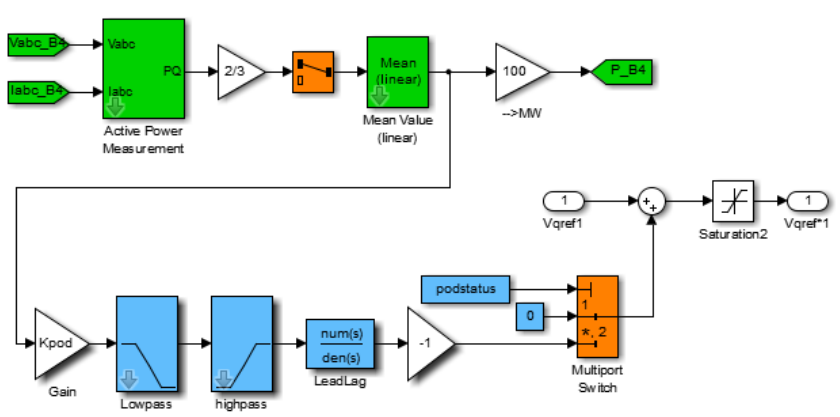

Fig 3 Simulink Model of POD controller

\section{TEST SYSTEM DESCRIPTION}

First, power system with four machines and six buses has been simulated in MATLAB environment, and then powers and voltages in all buses have been obtained. The results have been given in Table. Simulation results have been focused on bus-4 because of the variation in powers at this bus; it is selected as the candidate bus to which SSSC has to be installed [8]. In the simulation one SSSC has been utilized to control the power flow in the $500 \mathrm{KV}$ transmission systems. This system consisting of 6 buses (B1 to B6).The system has been supplied by four power plants with the phase-to-phase voltage equal to $13.8 \mathrm{kv}$ is shown 
in Fig 6. The SSSC located at bus B4 in series with line L2. It has a rating of $100 \mathrm{MVA}$ and is capable of injecting up to $10 \%$ of the nominal system voltage. This SSSC is a phasor model of a typical three-level PWM SSSC [8]. A SSSC having a DC link nominal voltage of $40 \mathrm{kV}$ with an equivalent capacitance of 375 $\mathrm{uF}$. On the AC side, its total equivalent impedance is $0.16 \mathrm{pu}$ on 100 MVA. This impedance represents the transformer leakage reactance and the phase reactor of the IGBT Bridge of an actual PWM SSSC [14].

\section{Simulation REsults AND STUdy CASES}

The simulation results are obtained for three cases.

1. Case Study 1. Test system without connecting SSSC Power flow under normal condition.

In this case SSSC is bypassed from the power system. The simulation results like voltage profile, active power and reactive power show the system performances under normal condition. Because of the ohmic loads the active power oscillations are more compared to reactive power oscillations [9]. The simulation diagram for a four machine six bus system without SSSC shown in Fig 4. The results have been given in Table.1

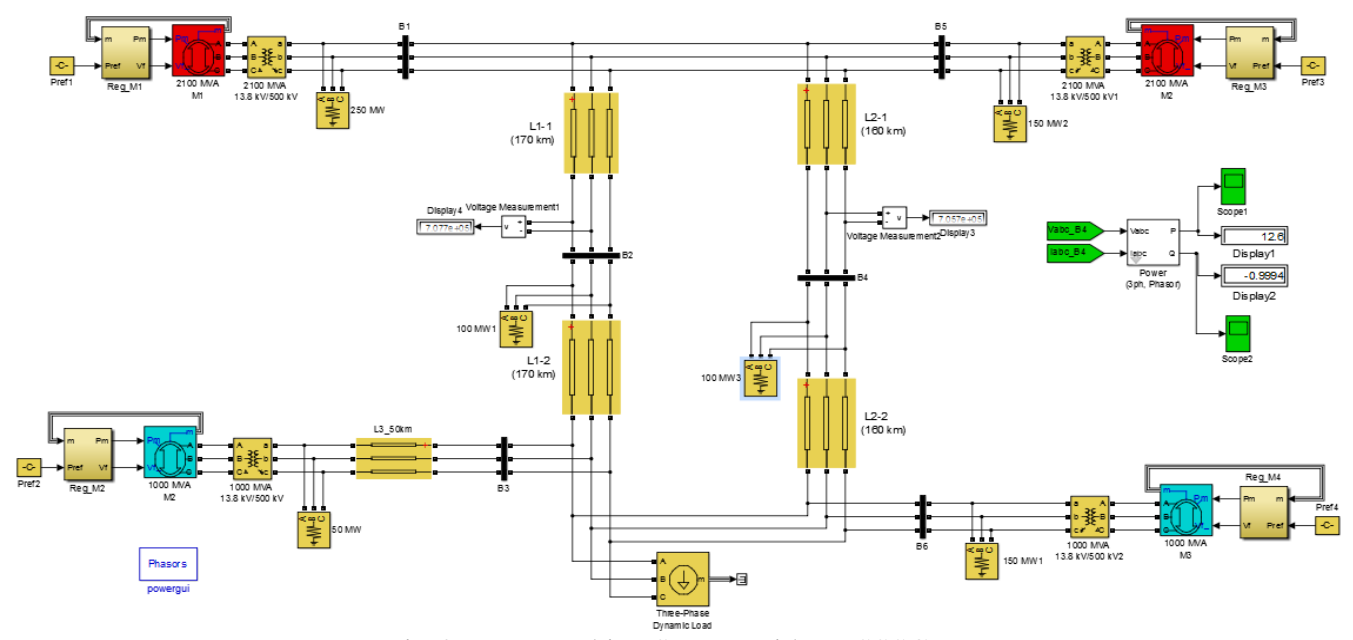

Fig.4. Four Machine System without SSSC

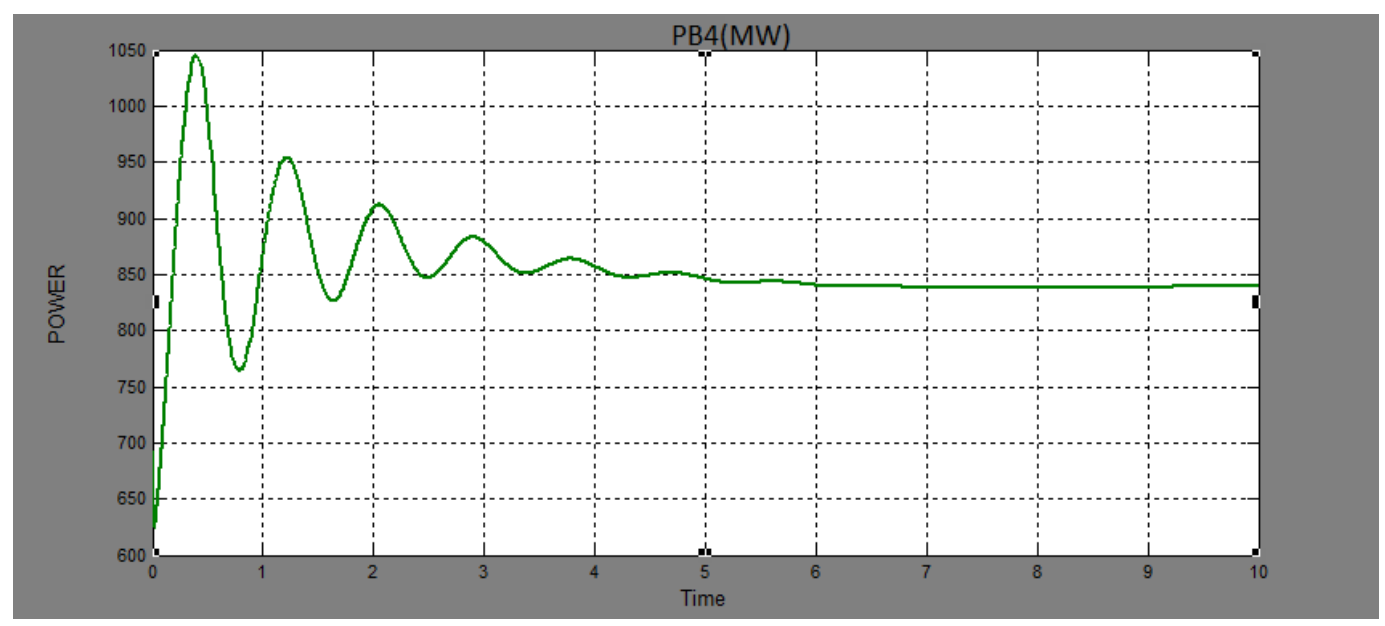

Fig. 5(a) Active Power at Bus 4 under normal condition for case 1 


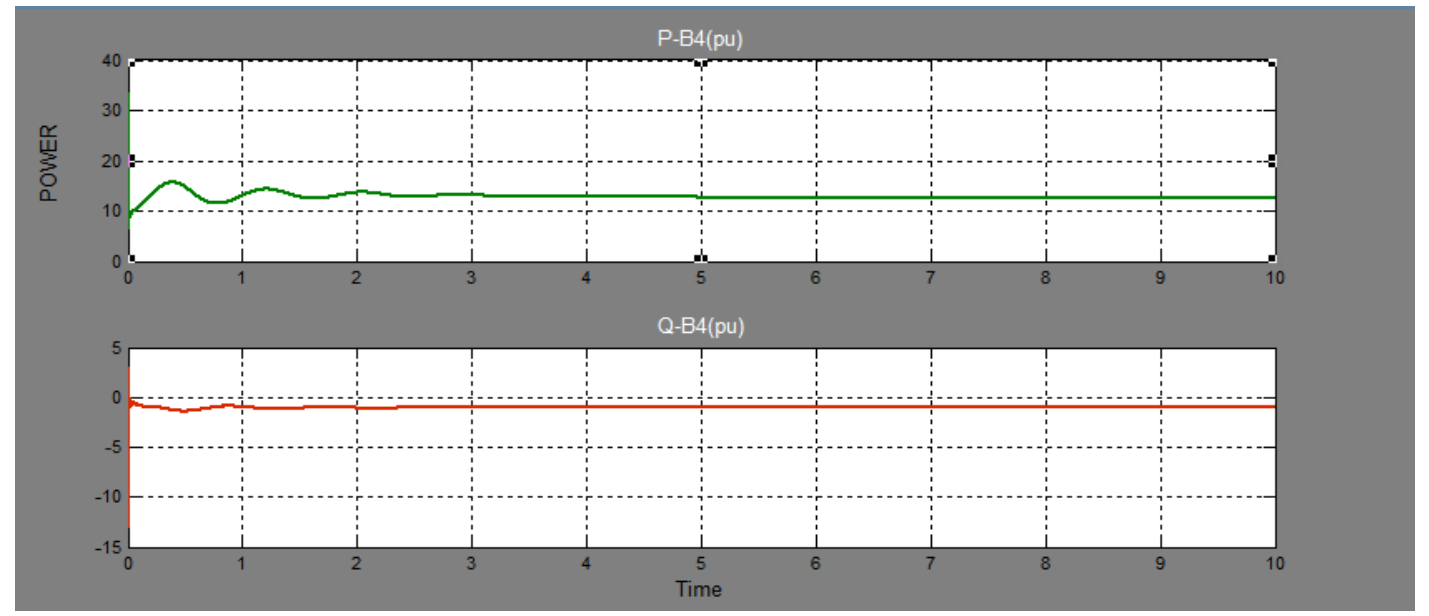

Fig. 5(b) Active \&Reactive Power (pu) at Bus 4 under normal condition for case 1

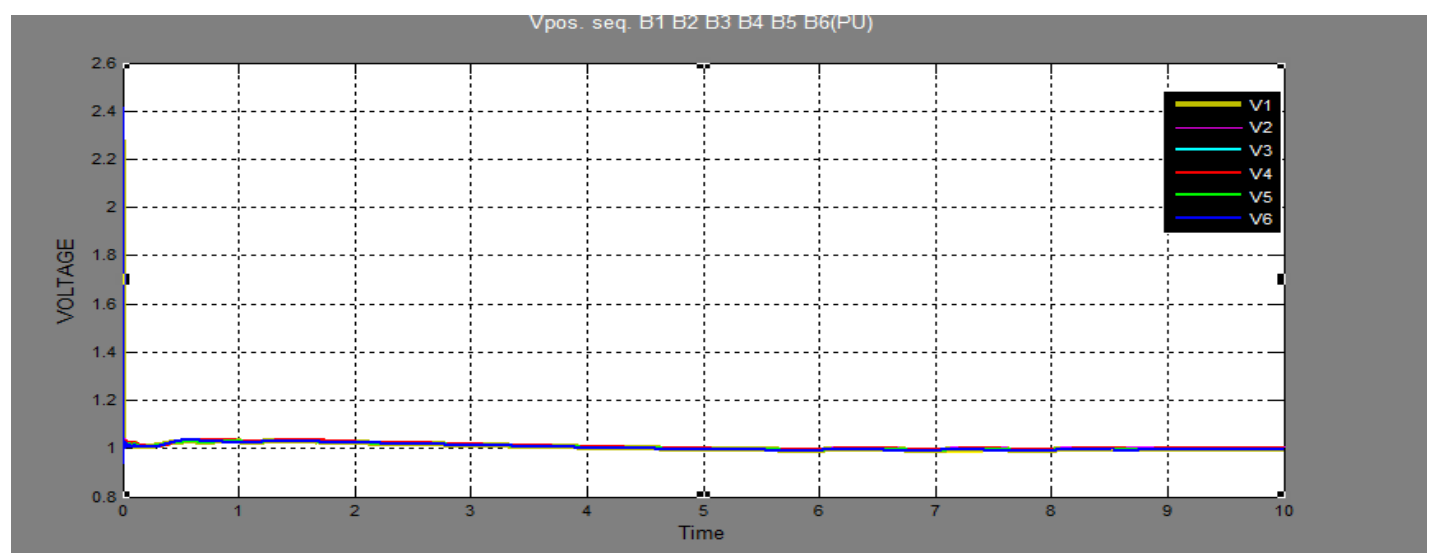

Fig. 5(c) Positive sequence voltages at all Buses for case 1

TABLE 1 SIMULATION RESULTS WITHOUT SSSC

\begin{tabular}{|c|c|c|c|c|}
\hline Bus no & Voltage & Current & Active power & Reactive power \\
\hline 1 & $1 \mathrm{pu}$ & $7.912 \mathrm{pu}$ & $11.71 \mathrm{pu}$ & $-1.5 \mathrm{pu}$ \\
\hline 2 & $1 \mathrm{pu}$ & $7.054 \mathrm{pu}$ & $10.44 \mathrm{pu}$ & $-0.956 \mathrm{pu}$ \\
\hline 3 & $1 \mathrm{pu}$ & $4.326 \mathrm{pu}$ & $6.403 \mathrm{pu}$ & $0.762 \mathrm{pu}$ \\
\hline 4 & $1 \mathrm{pu}$ & $8.513 \mathrm{pu}$ & $12.6 \mathrm{pu}$ & $-0.999 \mathrm{pu}$ \\
\hline 5 & $1 \mathrm{pu}$ & $-8.912 \mathrm{pu}$ & $-13.19 \mathrm{pu}$ & $1.535 \mathrm{pu}$ \\
\hline 6 & $1 \mathrm{pu}$ & $-3.337 \mathrm{pu}$ & $-4.94 \mathrm{pu}$ & $-0.55 \mathrm{pu}$ \\
\hline
\end{tabular}

2. Case Study 2. Test system with SSSC (when POD is off) normal condition and single \& three phase fault are considered

Initially Vqref is set to zero. At 2 sec. it is set to - 0.08pu which makes SSSC to operate in inductive mode. At 6 sec. Vqref is set to 0.08 pu which operates SSSC in capacitive mode. A single \& three phase fault is applied at Bus no. 2 at 0.33 sec.The simulation diagram for a 4 machine 6 bus system with SSSC shown in Fig 6. It is evident that after installation of SSSC the active power oscillation is reduced as shown in Fig. 7 and damping time will be less than the mode without SSSC. Also it improves the transient stability of the system. Results have been given in Table.2. In this case single phase fault \& three phase fault is applied at Bus no. 2 in attendance of SSSC at Bus no 4. The graph of voltage \& power are represented in Fig 8. It is clear that the SSSC maintain the flow of power constant during the fault. Also voltage in all buses remains 1p.u. 


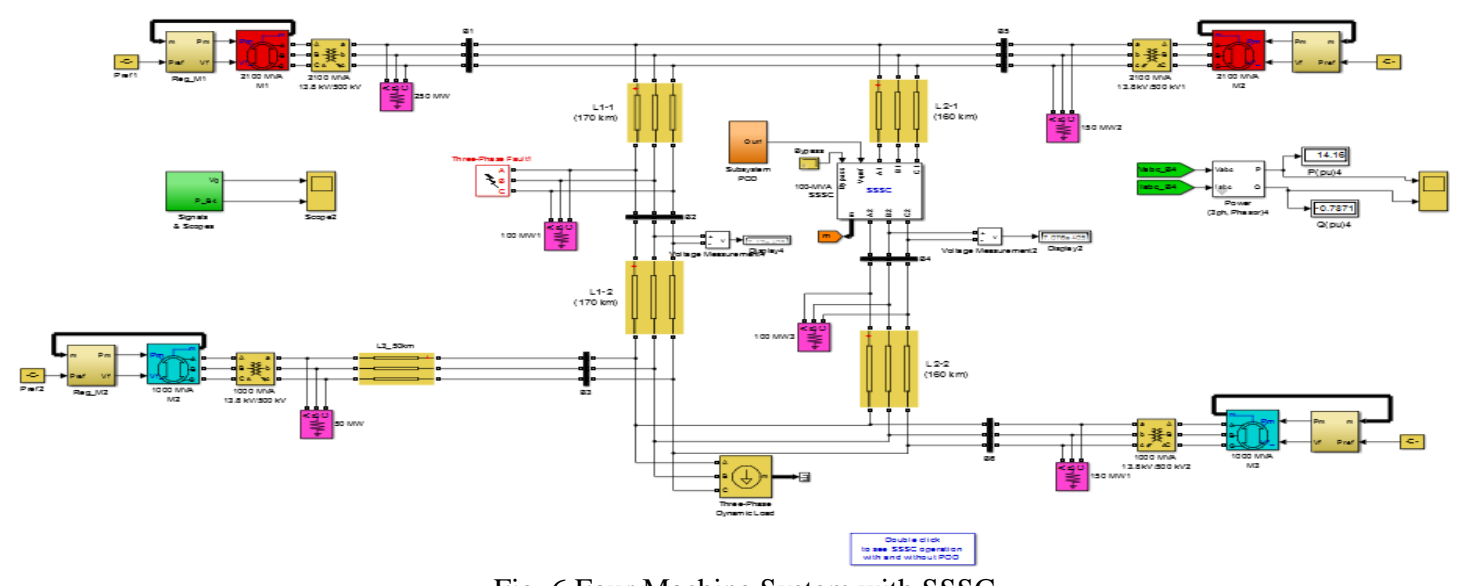

Fig. 6 Four Machine System with SSSC

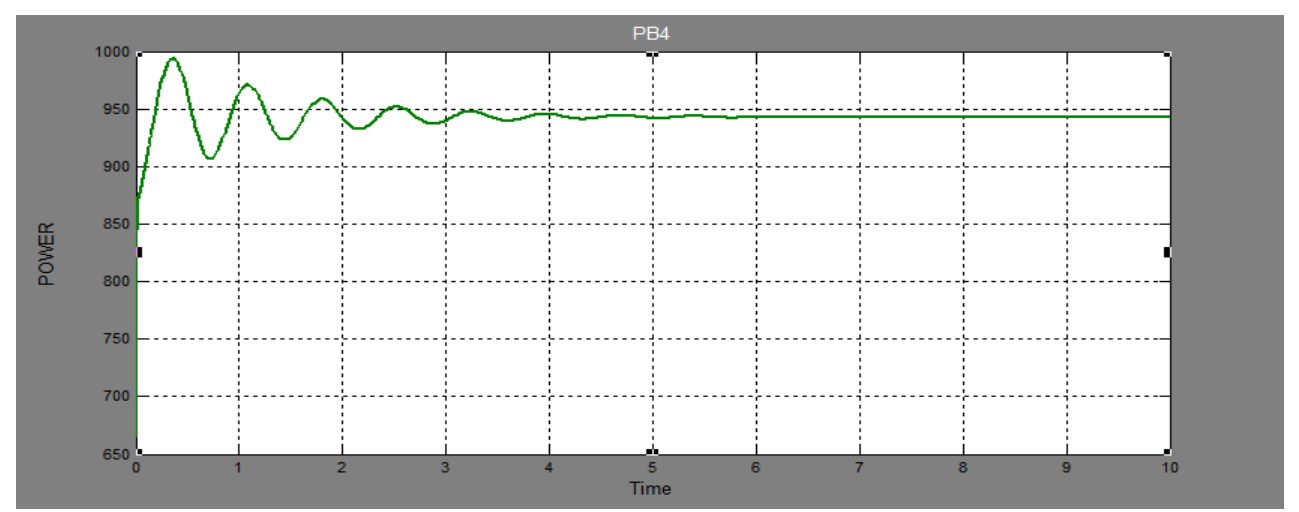

Fig. 7 Active Power at Bus 4 under normal condition for case 2

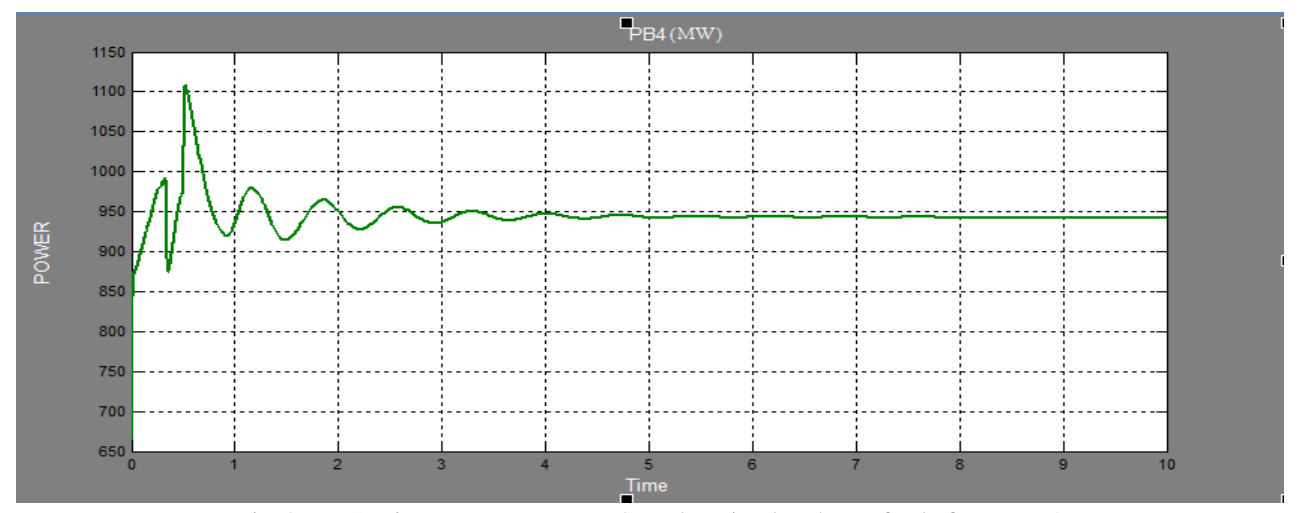

Fig.8 (a) Active Power at Bus 4 under single phase fault for case 2

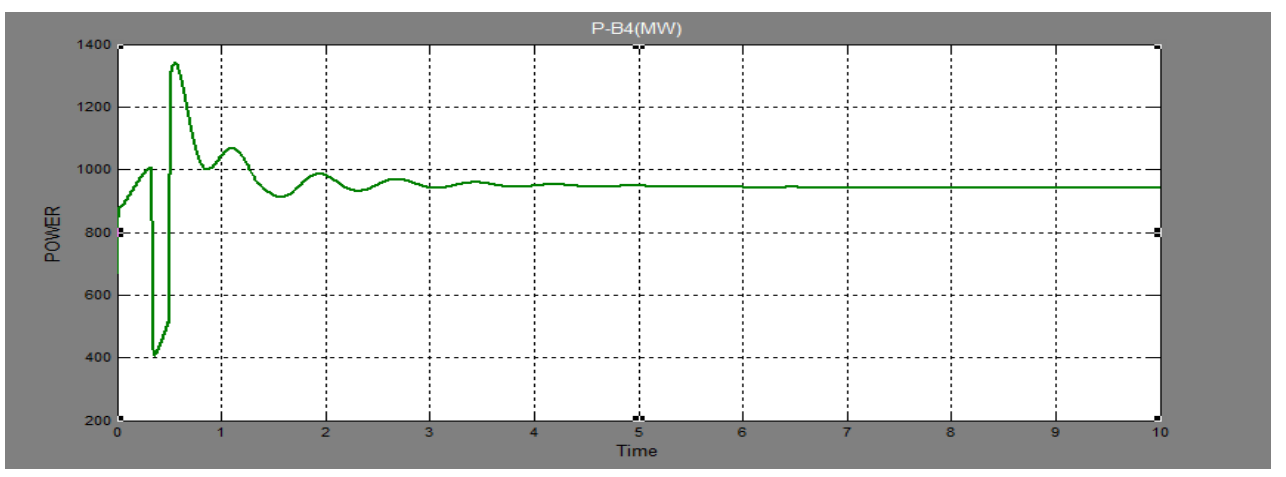

Fig.8 (b) Active Power at Bus 4 under three phase fault for case 2 


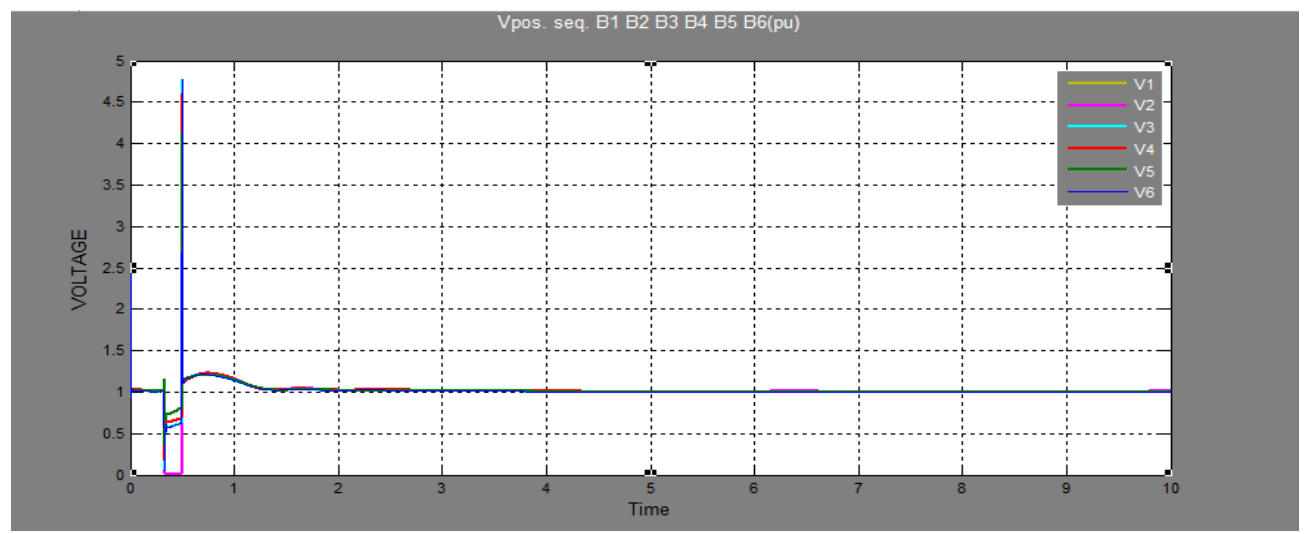

Fig.8 (c) Positive sequence voltages at all Buses under three phase fault for case 2

\begin{tabular}{|c|c|c|c|c|}
\hline \multicolumn{5}{|c|}{ TABLE 2 SIMULATION RESUlTS WITH SSSC } \\
\hline Bus no & Voltage & Current & Active power & Reactive power \\
\hline 1 & $1 \mathrm{pu}$ & $7.952 \mathrm{pu}$ & $11.77 \mathrm{pu}$ & $-2.013 \mathrm{pu}$ \\
\hline 2 & $1 \mathrm{pu}$ & $7.24 \mathrm{pu}$ & $10.44 \mathrm{pu}$ & $-0.822 \mathrm{pu}$ \\
\hline 3 & $1 \mathrm{pu}$ & $4.383 \mathrm{pu}$ & $6.487 \mathrm{pu}$ & $0.650 \mathrm{pu}$ \\
\hline 4 & $1 \mathrm{pu}$ & $9.567 \mathrm{pu}$ & $14.16 \mathrm{pu}$ & $-0.787 \mathrm{pu}$ \\
\hline 5 & $1 \mathrm{pu}$ & $-8.959 \mathrm{pu}$ & $-13.26 \mathrm{pu}$ & $2.013 \mathrm{pu}$ \\
\hline 6 & $1 \mathrm{pu}$ & $-3.331 \mathrm{pu}$ & $-4.931 \mathrm{pu}$ & $-0.371 \mathrm{pu}$ \\
\hline
\end{tabular}

3. Case Study 3. Test system with SSSC (when POD is on) normal condition and single \& three phase fault are considered

By installing the SSSC with POD the voltage stability has been enhanced and power oscillations are damped perfectly when compared to the four machine system without POD. The simulation results show that this controller gives best performance to the system during normal and fault condition. POD controller can accomplish oscillation damping, rapid response and finally stabilizing power system [10]. Fig 9 and Fig 10 show the voltage \& power response after implementing SSSC with POD. The overshoot of oscillation is slightly reduced if compare with case 2 without any controller.

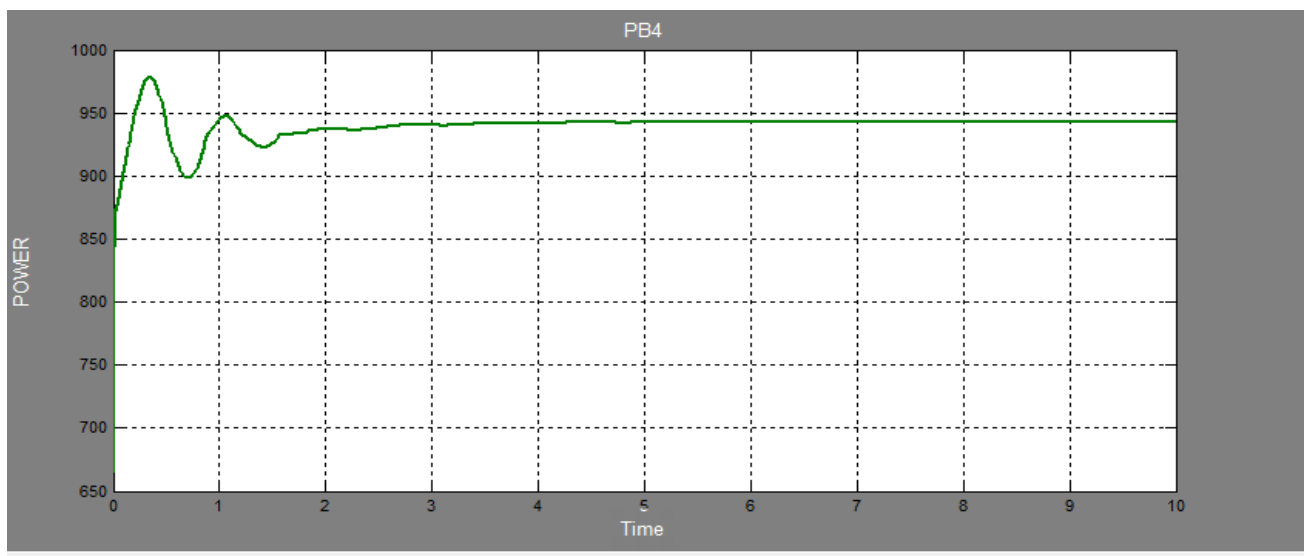

Fig.9 Active Power at Bus 4 under normal condition for case 3 


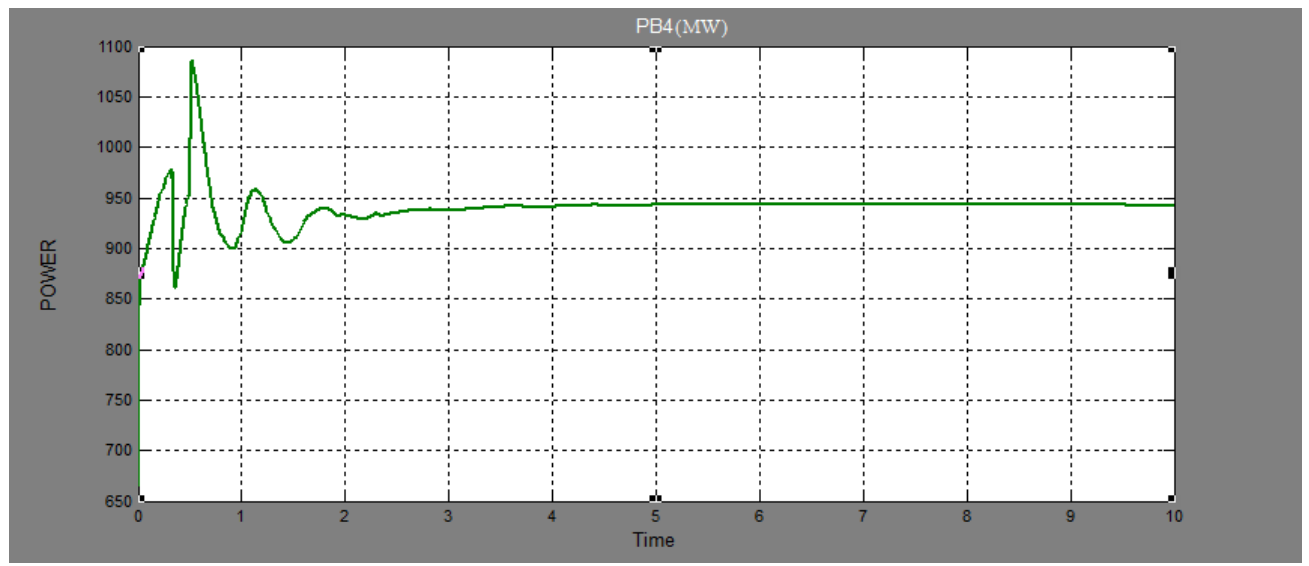

Fig. 10(a) Active Power at Bus 4 under single phase fault for case 3

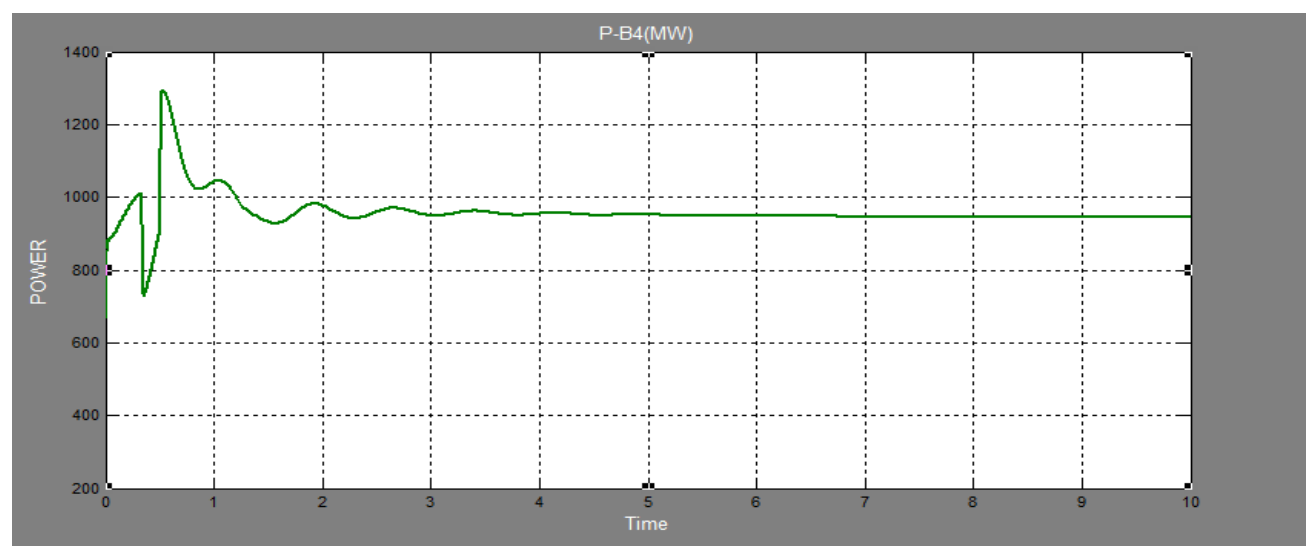

Fig. 10(b) Active Power at Bus 4 under three phase fault for case 3

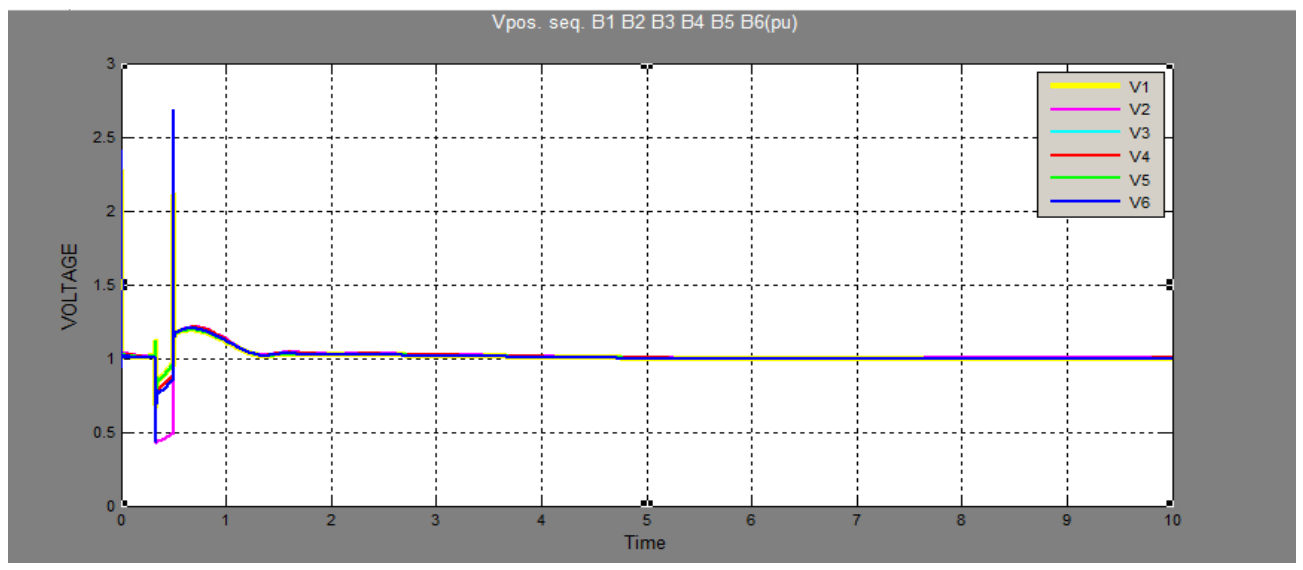

Fig. 10(c) Positive sequence voltages at all Buses under three phase fault for case 3

\section{CONCLUSION}

In this paper, the simulation of four-machine six Bus power system model with Static synchronous series compensator (SSSC) based damping controllers is performed. It can be clearly indicated that the static synchronous series compensator (SSSC) is capable of controlling the flow of power at a desired point on the transmission line by injecting a fast changing voltage in series with the line and it keeps the constant of power flow under fault conditions. The results show that the power system oscillations are damped out very quickly in few seconds. POD controller has been apply with SSSC for improving voltage profile and damping power oscillations. Active power damping time will be less than the mode without pod and it will be damped much faster. 


\section{REFERENCES}

[1] Akter, Samima, Anulekha Saha, and Priyanath Das. "Modelling, Simulation And Comparison Of Various FACTS Devices In Power System."International Journal of Engineering Research and Technology. Vol. 1. No. 8 (October-2012). ESRSA Publications, 2012.

[2] L.Gyugi, C.D. Schauder, and K.K. Sen. "Static synchronous series compensator: a solid-state approach to the series compensation of transmission lines”. IEEE Trans PowDeliv.1997.

[3] N.G. Hingorani, L. Gyugi. "Understanding FACTS: Concepts and Technology of Flexible AC Transmission Systems”. New York: IEEE Press; 2000.

[4] Maninder Rohal, Ravi. "Analysis of Power System Oscillation Damping \& Voltage Stability Improvement Using SSSC in A Multimachine System."International Journal of Engineering Research and Technology. Vol. 3. No. 7 (July -2014). ESRSA Publications, 2014.

[5] Mohan and R. K. Varma, Thyristor-Based FACTS Controllers for Electrical Transmission Systems. Piscataway, NJ: IEEE Press, 2002.

[6] F. Jowder. "Influence of mode of operation of the SSSC on the small disturbance and transient stability of a radial power system". IEEE Transactions on Power Systems, 20(2): pp.935-942.2005.

[7] Panda, Sidhartha. "Modelling, simulation and optimal tuning of SSSC-based controller in a multi-machine power system." World Journal of Modelling and Simulation 6.2 (2010): 110-121.

[8] Reddy, BM Naveen Kumar, Mr GV Rajashekar, and Himani Goyal. "Power System Stability Enhancement Using Static Synchronous Series Compensator (SSSC)." (2013).

[9] ] Sangeetha, C. N. "Enhancement of stability in multibus system using Static Synchronous Series Compensator (SSSC)."

[10] PramodKumar, K. Namrata. "Voltage Control and Power Oscillation Damping Of Multi-Area Power System Using Static Synchronous Series Compensator." (2012).

[11] Dua, Astha, and Surya Prakash. "Voltage Level Improvement Of Power System By Using Static Synchronous Series Compensator With POD."International Journal of Engineering Research and Technology. Vol. 2. No. 5 (May-2013). ESRSA Publications, 2013.

[12] Shankar, C. Udhaya, Rani Thottungal, and S. Mythili. "Stability Improvement and Power Oscillation Damping Using Static Synchronous Series Compensator (SSSC)." exchange 2.1 (2015).

[13] Rahman, Habibur, and Jewel Rana. "Power System Stability Improvement By Using SSSC With Power System Controller." International Journal of Science, Engineering and Technology Research 1.6 (2012): pp-28.

[14] MATLAB Math Library User's Guide", by the Math Works. Inc.

Rizan A. Ali Received B.Sc. degrees in Electrical Engineering from Electrical Engineering in Salahaddin University-Erbil, Iraq. Now she is master student in Electric and Electronic Engineering Department Gaziantep University, Turkey. She worked in Technology Institute, Ministry of Higher Education and Scientific Research of Erbil, Iraq. She is a member of Engineers Union in Erbil-Iraq.

Dr. Ergun Erceleb received B.S. degree in Electrical and Electronics Engineering from METU, Gaziantep, Turkey in 1990 and M.S. and Ph.D. degrees in Electrical and Electronics Engineering from University of Gaziantep in 1992 and 1999 respectively. He was the head of Computer Engineering, University of Gaziantep between 2003 and 2004. He is presently Professor and head of dept of electrical electronics department, University of Gaziantep. His research interests include speech processing, image processing, adaptive filters, neural networks, statistical signal processing wavelet. 